\title{
A literacia digital e as estratégias para o desenvolvimento de competências na aprendizagem em EAD: perspectivas do centro de recurso de Maputo, Moçambique
}

Olivia Maria Matusse

Doutoranda em Educação com especialidade em Inovação Educativa pela Universidade Católica de Moçambique. Docente na Universidade Eduardo Mondlane, na Faculdade de Educaşão, e diretora pedagógica do Instituto Superior Maria Mãe de África, Moçambique. E-mail: oliviamatusse7@hotmail.com

Eduardo Fofonca

Pós-doutorado pelo Programa de Pós-Graduação em Educação (Educação, Comunicação e Tecnologia) pela Universidade do Estado de Santa Catarina (Udesc). Lider do Grupo de Pesquisa "Educação a Distância e Tecnologias Digitais" (IFPR-CNPq).

E-mail: eduardofofonca@gmail.com

Resumo: Este artigo tem por finalidade apresentar uma breve reflexão sobre literacia digital dos estudantes da Educação a Distância (EaD) do Centro de Recursos de Maputo, da Universidade Católica de Moçambique. Objetiva-se perceber, sobretudo, como ocorre a literacia digital dos estudantes do curso on-line e como esta é compreendida por eles. Trata-se de uma pesquisa básica, de natureza qualitativa, porque busca compreender os fenômenos
Abstract: The purpose of this article is to present a brief reflection on digital literacy of distance education students $(\mathrm{EaD})$ of the Maputo Resource Center, Catholic University of Mozambique. It is intended to understand, above all, how the digital literacy of the students of the online course occurs and how it is understood by them. It is a basic qualitative research because it seeks to understand the phenomena in their natural environment, without any kind 
no seu ambiente natural, sem qualquer tipo de manipulação e, ainda, do tipo bibliográfico e documental, porque foi elaborada por meio de referenciais teóricos e documentos orientadores do Governo Moçambicano, que elucidam sobre as principais políticas das Tecnologias Digitais de Informação e Comunicação (TDIC) na EaD. De forma geral, foi possível perceber neste estudo que educar para a "tecnoliteracia" é um dos maiores desafios da educação neste século XXI, pois se vive em uma sociedade que migrou do meio geográfico (físico) para o meio virtual oferecido pela internet, o que mudou radicalmente a dinâmica das relações que envolvem a troca de informações. Diante desse contexto, a internet e a comunicação em rede trouxeram novas linguagens e a tessitura de textos mediados pelas TDIC.

Palavras-chave: literacia digital; Educação a Distância; competências; tecnoliteracia. of manipulation. It is also a bibliographic and documentary research because it was elaborated through theoretical references and government guidance documents from Mozambique, which elucidate the main policies of the TDIC (Digital Information and Communication Technology) in EaD. In general, it was possible to perceive in this study that educating for "techno-literacy" is one of the major challenges of education in the XXI century, since we live in a society that migrated from the geographic (physical) environment to the virtual environment offered by the Internet, which radically changed the dynamics of relations that involve information exchange. In this context, the Internet and networked communication have brought new languages and tessitura of texts mediated by the TDIC.

Keywords: digital Literacy; Distance Education; Skills; techno-literacy.
1. MELÃO, Dulce Helena. Ler na era digital: os desafios da comunicação em rede e a (re)construção da(s) literacia(s). Exedra Coimbra, n. 3, 2010, p. 78

2. LOUREIRO, Ana; ROCHA, Dina. Literacia digital e literacia da informação: competências de uma era digital. CONGRESSO INTERNACIONAL TIC E EDUCAÇÃO TIC EDUCA, 2., 2012, Santarém. Atas Santarém: Escola Superior de Educação do Instituto Politécnico de Santarém, 2012, p. 2727

3. LOUREIRO; ROCHA, op. cit., p. 2729.

\section{INTRODUÇÃO}

A cultura constitui-se pela ação do Homem na sociedade, como um reflexo dessa ação. O Homem cria formas, objetos, dando vida e significação a tudo o que o cerca. É essa ação humana que permitiu o surgimento do computador e, por conseguinte, o surgimento da cultura digital. Desse modo, observamos surgir uma nova estruturação de pensamentos, práticas e concepções. Assim, pode-se considerar que literacia prévia é um dos grandes problemas enfrentados hoje nesse processo pela busca do saber científico.

Etimologicamente, a palavra "literacia" designa a competência de ler. Portanto, se ler na era analógica seria a "capacidade para entender e usar a informação escrita no cotidiano, em casa, na escola e na comunidade, de forma a conseguir os objetivos pessoais e a desenvolver o próprio conhecimento e as capacidades próprias"1, ler na era digital torna-se a "capacidade que uma pessoa tem para desempenhar, de forma efetiva, tarefas em ambientes digitais - incluindo a capacidade para ler e interpretar os media, para reproduzir dados e imagens através de manipulação digital, avaliar e aplicar novos conhecimentos adquiridos em ambientes digitais"2.

Conforme apresentada, a concepção de "literacia digital" tornou-se mais abrangente e genérica, pois implica mais do que saber ler e escrever; denota a capacidade de compreender e utilizar a informação de várias fontes digitais. Dessa forma, a digitally literate pressupõe, parafraseando Loureiro e Rocha ${ }^{3}$, saber como aceder a informação e como a recolher em ambientes virtuais; gerir e organizá-la para utilização futura; avaliar, integrar, interpretar e comparar as 
informações de múltiplas fontes; criar e gerar conhecimento nas possibilidades de adaptar, aplicar e recriar uma nova informação; comunicá-la para diferentes meios, tendo em vista que estes devem estar adequados no processo interlocução (emissão-recepção).

Assim, as tecnologias digitais exigem o desenvolvimento de competências renovadas, lançando desafios educacionais que implicam e justificam uma expansão da concepção de literacia ${ }^{4}$. A falta de conhecimento do uso das Tecnologias Digitais da Informação e Comunicação (TDIC) em Moçambique, particularmente na Educação a Distância $(\mathrm{EaD})$, gera dificuldades nos processos de ensino e aprendizagem, uma vez que os docentes, para além de lecionar os conhecimentos que cabem em suas disciplinas, devem fazer também certas introduções e diálogos sobre as TDIC na sociedade contemporânea, pois essa falta de familiarização com a internet com os recursos da web faz o estudante sentir-se (des)integrado do contexto social que tanto absorve e integra as tecnologias digitais, tanto em sua utilização social como na compreensão da linguagem utilizada virtualmente.

\section{INDICADORES E MAPA DAS QUESTÕES PESQUISADAS}

As questões da pesquisa em tela foram compostas a partir do seguinte problema de pesquisa: o nível de literacia digital dos estudantes do Centro de Recursos de Maputo $^{5}$ (CRM) constitui algum obstáculo para a sua aprendizagem? Ainda assim, outras questões não menos importantes estiveram presentes na constituição da pesquisa, tais como: os perfis, as características e as especificidades inerentes ao estudante nesta era digital; o nível de literacia digital dos estudantes que acedem aos cursos on-line no Centro de Ensino a Distância (CED); as condições materiais dos estudantes (equipamentos e acesso à internet), bem como as oferecidas pelo CED, na formação nessa modalidade de ensino, são facilitadoras ou inibidoras do sucesso escolar dos estudantes? Quais políticas internas de apoio ao estudante foram desenvolvidas pelo CED como mecanismos de suporte ao estudante, com vistas a torná-lo proficiente no contexto digital? Contudo, o objetivo deste estudo foi o de compreender como ocorre a literacia digital entre os estudantes e como ela é compreendida por estes que atuam na modalidade a distância. Assim, para alcançar esse propósito, foram elaborados alguns objetivos específicos:

a) desenvolver uma perspectiva conceptual de competências pessoais, tecnológicas e comunicacionais do estudante do CED;

b)identificar os recursos e os principais elementos tecnológicos que facilitam a construção de uma possível literacia digital desses estudantes;

c) indicar os mecanismos de apoio ao estudante desenvolvido pelo CED, com vistas ao seu desenvolvimento de competências digitais.
4. Cf. SANTOS, Rita; AZEVEDO, José; PEDRO, Luís. Literacia(s) digital(ais): definições, perspetivas e desafios. Media \& Jornalismo, Lisboa, v. 15, n. 27, p. 27-44, 2015.

5. O CRM, que serve de objeto de estudo, tem a sua equipe de trabalho constituída por uma coordenadora de programas, um assistente pedagógico e outros funcionários que garantem o decurso normal da aprendizagem dos estudantes. É uma entidade autónoma pertencente ao Centro de Ensino a Distância; ela tem os seus próprios cursos que são coordenados pelo CED. 
Torna-se importante destacar que esta é uma pesquisa de natureza qualitativa, que pretende proporcionar uma maior familiaridade com o problema, tornando-o mais explícito ${ }^{6}$; considerando, também, uma revisão da literatura para compreender o problema à luz de referências do campo das tecnologias na/em educação. A partir das questões de pesquisa delineadas, foram elaboradas as dimensões de pesquisa e, destas, os respectivos indicadores (Quadro 1). Ressalta-se que os indicadores são as manifestações objetivamente observáveis e mensuráveis das dimensões de pesquisa ${ }^{7}$; portanto, os instrumentos de seleção e organização dos dados irão corroborar para que se obtenha os dados listados nesses indicadores.

\section{Quadro 1: Indicadores da pesquisa}

\begin{tabular}{|c|c|c|c|}
\hline $\begin{array}{l}\text { SUBQUESTÕES } \\
\text { DE PESOUISA }\end{array}$ & DIMENSÕES & INDICADORES & COMPETÊNCIAS \\
\hline \multirow[t]{3}{*}{$\begin{array}{l}\text { 1. Qual é o } \\
\text { nível de literacia } \\
\text { digital dos } \\
\text { estudantes que } \\
\text { acedem aos } \\
\text { cursos on-line no } \\
\text { CED? }\end{array}$} & \multirow[t]{3}{*}{$\begin{array}{l}\text { Competência } \\
\text { Digital }\end{array}$} & $\begin{array}{l}\text { Situação Profissional: } \\
\text { considerando atributos } \\
\text { ou habilidades } \\
\text { associadas ao } \\
\text { desempenho de seu } \\
\text { cargo profissional. }\end{array}$ & \multirow{3}{*}{$\begin{array}{l}\text { Usar com proficiência os } \\
\text { instrumentos de comunicação } \\
\text { em ambiente virtual (abrir } \\
\text { documentos; abrir mensagens } \\
\text { nos fóruns; responder a } \\
\text { mensagem nos fóruns; receber } \\
\text { e enviar ficheiros; fazer uploads } \\
\text { e downloads; submeter } \\
\text { trabalhos etc.). } \\
\text { Fazer apresentações on-line. } \\
\text { Participar em discussões on-line. }\end{array}$} \\
\hline & & $\begin{array}{l}\text { Profissional para } \\
\text { autodidatismo. }\end{array}$ & \\
\hline & & $\begin{array}{l}\text { Formação pré- } \\
\text { universitária (verificar } \\
\text { se tiveram iniciação em } \\
\text { informática). }\end{array}$ & \\
\hline $\begin{array}{l}\text { 2. As condições } \\
\text { materiais dos } \\
\text { estudantes } \\
\text { (materiais } \\
\text { e acesso à } \\
\text { internet), } \\
\text { bem como } \\
\text { as ofertadas } \\
\text { pelo CED são } \\
\text { facilitadoras ou } \\
\text { inibidoras do } \\
\text { sucesso escolar } \\
\text { dos estudantes? }\end{array}$ & $\begin{array}{l}\text { Condições } \\
\text { materiais dos } \\
\text { estudantes. }\end{array}$ & $\begin{array}{l}\text { Verificação do que se } \\
\text { refere aos equipamentos } \\
\text { informáticos: } \\
\text {-Posse de um } \\
\text { computador; } \\
\text {-Acesso à internet } \\
\text {-Posse de celular; } \\
\text {-Práticas e frequência de } \\
\text { uso da internet; } \\
\text {-Ligação a alguma rede } \\
\text { de internet. }\end{array}$ & $\begin{array}{l}\text { Usar com proficiência os } \\
\text { instrumentos de comunicação } \\
\text { em ambiente virtual (abrir } \\
\text { documentos; abrir mensagens } \\
\text { nos fóruns; responder a } \\
\text { mensagem nos fóruns; receber } \\
\text { e enviar ficheiros; fazer uploads } \\
\text { e downloads; submeter } \\
\text { trabalhos etc.). } \\
\text { Fazer apresentações on-line. } \\
\text { Participar em discussões on-line. }\end{array}$ \\
\hline $\begin{array}{l}\text { 3. Quais } \\
\text { políticas internas } \\
\text { de apoio aos } \\
\text { estudantes foram } \\
\text { desenvolvidas } \\
\text { pelo CED como } \\
\text { mecanismo } \\
\text { de suporte ao } \\
\text { estudante com } \\
\text { vistas a torná- } \\
\text { lo competente } \\
\text { digital? }\end{array}$ & $\begin{array}{l}\text { Mecanismos } \\
\text { de apoio. }\end{array}$ & $\begin{array}{l}\text { Espaços e equipamentos } \\
\text { informáticos; } \\
\text { Políticas internas; } \\
\text { Intervenientes no } \\
\text { processo; } \\
\text { Intervenientes na } \\
\text { comunicação. }\end{array}$ & $\begin{array}{l}\text { Usar com proficiência os } \\
\text { instrumentos de comunicação } \\
\text { em ambiente virtual (abrir } \\
\text { documentos; abrir mensagens } \\
\text { nos fóruns; responder a } \\
\text { mensagem nos fóruns; receber } \\
\text { e enviar ficheiros; fazer uploads } \\
\text { e downloads; submeter } \\
\text { trabalhos etc.). } \\
\text { Fazer apresentações on-line. } \\
\text { Participar em discussões on-line. }\end{array}$ \\
\hline
\end{tabular}

6. GERHARDT, Tatiana Engel; SILVEIRA, Denise Tolfo. Métodos de Pesquisa. Porto Alegre: UFRGS Editora, 2009.

7. QUIVY, Raymond; CAMPENHOUDT, Luc Van. Manual de investigação em Ciências Sociais. 2. ed. Lisboa: Gradiva, 1995. 
Desse modo, o questionário aplicado aos gestores do curso e de programas on-line do CED e do CRM objetivava perceber e compreender as experiências de aprendizagem dos estudantes no Ambiente Virtual de Aprendizagem (AVA). Assim, para contextualizar melhor essa abordagem, parte-se do que está previsto como política de inclusão digital, como ações do governo de Moçambique.

\section{POLÍTICAS DE INCLUSÃO DIGITAL}

As políticas públicas de inclusão digital em Moçambique tiveram um grande avanço nos primeiros momentos da década 1990, todavia desde então foram perdendo a sua força como política e ação política. De acordo com Joanguete ${ }^{8}$, hoje se apresentam alguns projetos poucos de inclusão digital, sobretudo no campo da educação e das comunidades rurais. Uma das suas limitações é a tendência em apostar mais na inclusão da população urbana, em detrimento das regiões periféricas e rurais, que constituem um grande número da população moçambicana. Pode-se considerar que é a partir das regiões periféricas e rurais que deve ser iniciada a construção de uma cidadania ativa e participativa na sociedade, pois são estes atores que constituem a população-alvo do estudo em questão.

a) A Política de Informática (PI), aprovada em 2000, aposta na promoção e expansão das novas tecnologias como uma alavanca para o desenvolvimento do país; os desafios dessa Política foram desenvolvidos na Estratégia de Implementação da Política de Informática (EIPI), aprovada em junho de 2002. Ela tem como objetivos centrais - entre muitos - elevar a consciência das pessoas sobre as TDIC e o seu potencial para o desenvolvimento, dando acesso universal à informação, de forma que os cidadãos possam melhorar o seu desempenho profissional e obtenham benefícios em áreas como educação, ciência e tecnologia, saúde e cultu$\mathrm{ra}^{9}$. Essa Política menciona de forma particular o potencial das TDIC na EaD. Outro avanço importante decorrente da Política de Informática foi a criação da Rede de Educação e Pesquisa de Moçambique ${ }^{10}$ (MoRENet - Mozambique Research and Education Network). Esse projeto também permite o acesso à educação por via de sistema de ensino à distância, usando as TIC a todos os níveis.

b) Desde 2003, Moçambique dispõe de uma Política de Ciência e Tecnologia (PCT) de base transversal, que também tem como objetivo principal estimular a inovação nacional em benefício do desenvolvimento e do combate à pobreza que afeta a população moçambicana. Essa Política está baseada em quatro pilares: educação, investigação, atividades produtivas e disseminação.

c) O Plano Tecnológico da Educação (PTE) é outro documento normativo importante que enfatiza as potencialidades das TDIC para a expansão da oferta educativa e melhoria dos processos de ensino e aprendizagem.
8. JOANGUETE, Celestino. Política pública moçambicana sobre a inclusão digital. Redmarka: Revista Acadêmica de Marketing Aplicado, Buenos Aires, v. 3, n. 7, p. 61-82, 2011.

9. MALEANE, Susana Otília Tomás. Tecnologias de informação e comunicação como um meio de inclusão e exclusão social em Moçambique: o caso do ensino superior. 2012. $159 \mathrm{f}$. Tese (Doutorado em Ciências da Informação) Universidade de Brasília, Brasília, DF, 2012.

10. Esse projeto, desenvolvido pelo Ministério da Ciência e Tecnologia (MCT), faz a conexão atualmente entre 19 instituições de ensino superior (IES), em uma rede da internet de alta velocidade (10-34 Mbps), com vistas a transformar qualitativa e quantitativamente a capacidade de busca e partilha de conhecimento, a cooperação nacional e internacional em projetos de pesquisa e o acesso a recursos como a biblioteca e ferramentas de ensino-aprendizagem (EA). 
d) O Plano Estratégico da Educação (PEE) para os próximos anos vai incluir a elaboração de uma política e estratégia de EaD. Além disso, desenvolve o sistema de acreditação e garantia de qualidade, a consolidação dos vários programas e iniciativas em curso nessa linha, a implementação dos projetos-piloto do Instituto Nacional de Educação a Distância (Ined) e a construção e consolidação da rede dos Centros Provinciais de EaD. Essas ações têm como objetivo central aumentar e diversificar a oferta educativa em diferentes níveis de ensino ${ }^{11}$.

É relevante destacar que a Estratégia da Educação à Distância (EEAD) para o período de 2014 a 2018 é garantir o direito à educação a todos os cidadãos moçambicanos. De acordo com o documento do Conselho de Ministros de Maputo $^{12}$, espera-se que essa estratégia propicie uma linha de orientação para aprofundar o uso da modalidade da EaD na redução da discrepância entre a procura e a oferta, maximizando o uso das TDIC no aprimoramento do direito à educação e da criação de mecanismos de garantia de qualidade na oferta de cursos e programas. Contudo, apesar de todas as políticas e seus respectivos planos de implementação, os estudantes continuam com dificuldade para assimilar as denominadas competências digitais, essenciais para seu êxito em cursos na modalidade de EaD.

11. MINISTÉRIO DA EDUCAÇÃO DA REPÚBLICA DE MOÇAMBIQUE. Plano Estratégico da Educação 2012-2016. Maputo: Mined, 2012.

12. CONSELHO DE MINISTROS. Estratégia da Educação a Distância 2014-2018. Maputo: Conselho de Ministros, 2013.

13. INSTITUTO NACIONAL DE ESTATÍSTICA.

Estatísticas e indicadores sociais, 2012-2013. Maputo: INE, 2013.

14. JOANGUETE, op. cit.

15. Segundo os dados estatísticos, o incremento do acesso à internet em Moçambique cresceu, de 2010 a 2014, de $4,2 \%$ a $5,9 \%$, cerca de 1\%. Cf. INTERNATIONAL TELECOMMUNICATION UNION. Measuring the Information Society Report 2015. Geneva: ITU, 2015.

\section{1 Índice de inclusão digital e experiências de EaD em Moçambique}

Segundo dados do Instituto Nacional de Estatística ${ }^{13}$, Moçambique possui cerca de 24,4 milhões de habitantes, dos quais 36,4\% residem nas zonas urbanas e $68,6 \%$ nas zonas periféricas e rurais. Nesse sentido, considera-se que residem nestas zonas (periféricas e rurais) a maior parte dos estudantes da modalidade de EaD do CRM. As estatísticas sobre inclusão digital em Moçambique revelam que somente esse número reduzido de cidadãos, moradores das zonas urbanas, são beneficiários do conhecimento, das ferramentas de informática e da internet, mesmo com as diferentes políticas e projetos criados pelo governo, com o intuito de incluir o cidadão na nova sociedade baseada na informação.

Joanguete $^{14}$ também afirma que, relativamente à percentagem de cobertura dos serviços de internet, somente a cidade de Maputo dispõe de uma cobertura de $100 \%$, seguida da província de Maputo, com 37,5\% de cobertura; as restantes províncias e distritos têm muito pouco acesso. Esses dados demonstram que Moçambique, apesar de ter sido o terceiro país do continente africano a aderir ao uso das tecnologias, é o que possui uma das coberturas de internet menos desenvolvidas da África, além de seus elevados custos e o acentuado nível de analfabetismo que assola o país ${ }^{15}$. Como é percebido, apesar de todo o esforço do governo, ainda há muito por se fazer. 
É importante que as IES se lembrem de que o advento das tecnologias de informação e comunicação (TIC), em geral, trouxe para todo o mundo - e não menos a Moçambique - um gradual aumento dos cursos à distância, nas suas diferentes modalidades e, com ela, surge também um novo tipo de discentes, com novo perfil e competências. Nota-se também um aumento exponencial da procura desse tipo de ensino, principalmente por estudantes imigrantes digitais (com problemas de literacia prévia). Porém, esse aumento da procura dos cursos não é proporcional ao incremento do acesso dos estudantes à internet. Segundo os dados estatísticos, o aumento do acesso à internet em Moçambique, entre 2010 a 2014 , foi de $4,2 \%$ para $5,9 \%$, cerca de $1 \%{ }^{16}$ - um aumento quase insignificante.

As experiências do EaD em Moçambique nasceram de uma forma bastante peculiar, no meio de um caos: a Guerra Civil que flagelou Moçambique de 1977-1992. O III Congresso do partido Frelimo, que aconteceu em 1977, tinha como um dos seus pontos de agenda a questão do acesso à educação para todos os moçambicanos. Nesse Congresso foram emanadas orientações para o desenvolvimento de um estudo de viabilidade até 1979, para se apurarem as condições existentes para o estabelecimento de um centro nacional de ensino por correspondência.

O ponto mais alto dessas iniciativas governamentais foi a criação do Instituto Nacional de Educação à Distância (Ined) em 2006. Com a criação do Ined, o governo assume de forma clara esse projecto de $\mathrm{EaD}$, com vistas a atender as necessidades de desenvolvimento do capital humano, em um contexto de globalização, competitividade e mudanças tecnológicas.

Essas mudanças tecnológicas ocorridas ao longo da história do EaD em Moçambique, caracterizadas pelo tipo de materiais utilizados para o efeito (geração da inovação tecnológica), tiveram uma importância sem igual no desenvolvimento do EaD.

De forma geral, em Moçambique, a provisão de cursos à distância situa-se entre a $2^{a 17}$ e a $4^{\text {a18 }}$ geração, com grande ênfase para os materiais impressos e o uso da internet ${ }^{19}$. Este estudo incidiu sobre a $4^{\text {a }}$ geração de inovação tecnológica - a geração do e-learning - que surgiu com a evolução das TIC e das comunicações em redes de computadores; Linda Harasim e Anthony Kaye foram seus principais mentores.

A integração das TIC no processo educacional pode representar um salto qualitativo no conjunto de todo o sistema de ensino e aprendizagem. Contudo, devido ao acentuado déficit no seu acesso e uso por parte de largas camadas da sociedade, essas tecnologias poderão continuar a constituir-se em um instrumento muito forte de exclusão e desigualdades sociais. Conforme analisado, é importante integrar as tecnologias digitais nos processos de ensino e aprendizagem, principalmente quando se trata de um ensino em AVA. Porém, para uma integração eficaz, tornou-se necessário que os cidadãos adquirissem um conjunto de competências adicionais às requeridas por tecnologias anteriores. Sendo assim, o sucesso da $\mathrm{EaD}$ vai depender do uso eficaz da tecnologia digital,
16. INTERNATIONAL COMUNICATION UNION, op. cit.

17. $2^{\text {a }}$ Geração: conhecida como a geração multimídia, surge com o advento das Universidades Abertas, na década de 1970, que fazem o uso combinado de vários meios de ensino, como o material impresso, o rádio, a televisão, cassetes em áudio e vídeo.

18. $4^{a}$ Geração: é a geração da aprendizagem flexível com o apoio da Internet. É o chamado e-learning.

19. CONSELHO DE MINISTROS. Estratégia da Educação a Distância 2014-2018. Maputo: Conselho de Ministros, 2013. 
20. SANTOS, Rita; AZEVEDO, José; PEDRO, Luís. Literacia(s) digital(ais): definições, perspetivas e desafios. Media \& Jornalismo, Lisboa, v. 15, n. 27, p. 27-44, 2015.

21. BUCUTO, Manuel; ALMEIDA, Leandro; ARAÚJO, Alexandra. Expectativas acadêmicas de estudantes universitários em Moçambique: validação de uma versão do questionário de percepções acadêmicas (QPA - Expectativas). In: SEMINÁRIO INTERNACIONAL COGNIÇÃO, APRENDIZAGEM E RENDIMENTO, 1., 2014, Braga. Anais... Braga: Universidade do Minho, 2014. p. 60-7. como dos computadores, das redes informáticas, dos personal digital assistants (PDA), dos celulares, entre outros objetos digitais (OD). Diante disso, conhecer o funcionamento desses equipamentos, assim como seus programas informáticos associados, é fundamental para o sucesso da modalidade em qualquer lugar do mundo, pois aumenta significativamente a probabilidade de utilizá-los de forma mais eficaz ${ }^{20}$.

Por esse motivo o Governo moçambicano, tal como fizeram os outros, começou a apostar em novas alfabetizações que possam garantir a criação de habilidades e competências que permitam aos estudantes aprenderem em ambiente virtual. A expectativa é de que, em um futuro próximo, esses estudantes que acedem aos cursos on-line do CED, em particular, tenham um conhecimento básico da internet, incluindo a forma de usar um navegador para acessar ao site do curso, como trabalhar em ambiente on-line, como fazer pesquisas básicas, enviar e-mails, usar um processador de textos, entre outras competências digitais úteis para a sua formação.

Desse modo, torna-se relevante destacar que no contexto da inovação pedagógica, as experiências inovadoras no ensino superior (ES) envolvem a articulação dos conhecimentos disciplinares com o uso das TDIC; a promoção e o desenvolvimento de competências para planejar diversas atividades com o uso destas; o acompanhamento e avaliação dos alunos por meio dos recursos TDIC; a renovação dos planos e programas dos cursos universitários, incorporando TDIC como ferramenta didática de planejamento e desenvolvimento profissional. Em Moçambique são raros os estudos desenvolvidos nessa área, mas em um dos estudos feitos em seis escolas da cidade de Maputo, tanto os professores quanto os alunos envolvidos no estudo consideram as experiências de aprendizagem com recursos às TDIC motivadoras. Apesar disso, pouco fazem uso dessas tecnologias na realização de tarefas escolares alegando, em sua maioria, a falta de incentivo ou até proibição por parte dos professores. Quanto aos professores envolvidos no estudo, poucos deles utilizam ou incentivam o uso das TDIC no processo educativo.

\section{COMPETÊNCIAS DIGITAIS DOS ESTUDANTES DE EDUCAÇÃO A DISTÂNCIA}

Relativamente a esse aspecto, é importante destacar que estudos desenvolvidos recentemente ${ }^{21}$ revelam que os estudantes do EAD em Moçambique chegam com fracas capacidades e bases de conhecimentos para enfrentarem as exigências do ES. Esses estudos consideram a heterogeneidade em termos de conhecimentos, de habilidades cognitivas e de motivação, como um dos fatores que provocam o insucesso desses estudantes na sua formação superior.

A constatação mais habitual é a de que há uma lacuna de conhecimentos por parte dos estudantes na fase de transição. Os estudantes saem do ensino médio com problemas em resolver operações básicas de matemática e de 
interpretação de texto. Há autores mais críticos que afirmam que muitos dos estudantes que ingressam no ensino superior completam o ensino médio praticamente semianalfabetos.

Nos questionários aplicados, os respondentes afirmam que uma das principais dificuldades com que deparam estão ligadas a problemas básicos de leitura, escrita, interpretação de texto, estruturação de pensamentos, entre outros; têm fraca cultura de leitura e, como consequência, são dependentes dos professores e dos materiais didácticos. Também apresentam problemas ligados à fraca capacidade de uso de ferramentas informáticas. Muitos deles chegam ao ensino superior sem passar por um curso de iniciação à informática, outros ainda sem nunca terem desfrutado da oportunidade de manusear um computador.

Portanto, esse assunto é de extrema importância, porque sabe-se que os utilizadores dessas tecnologias deixaram de ser meros receptores passivos da informação e do conhecimento e passaram a ser utilizadores activos e reactivos da informação e do conhecimento, buscando, construindo, criando, partilhando e comentando conteúdos e contextos, contribuindo para uma melhor colaboração no processo de construção do conhecimento.

Como mecanismo de suporte para melhorar as suas competências digitais, o CED oferece:

a) Um módulo de ambientação que normalmente acontece duas semanas antes do início das aulas.

A Universidade Aberta de Lisboa (UAb) tem desenvolvidos vários estudos nessa área, e uma das principais estratégias adotadas para contribuir com a literacia digital do aluno determina que todos eles devem participar de um "Módulo de ambientação". Trata-se de um curso realizado duas semanas antecedentes ao início das disciplinas. Esse módulo é fundamental para que o aluno se prepare para participar de um curso on-line. Tecnicamente, o referido Módulo prepara os alunos para o uso dos principais recursos utilizados pelos docentes durante o curso, que são os disponíveis no Moodle, principalmente os fóruns de discussão, os links para arquivos, Wiki, filmes disponibilizados no YouTube, jogos educativos e artigos disponíveis na internet ${ }^{22}$.

Esses módulos introdutórios, para além de ensinar competências instrumentais, como acessar o Moodle e seus recursos, visam, sobretudo, que os alunos percebam como atuar em um cenário de aprendizagem virtual e como comunicar-se com os demais participantes da formação. Sendo que os estudantes do CRM não têm muita experiência com o computador, nesse módulo há uma espécie de subinformação. Eles recebem muita informação ao mesmo tempo sobre áreas que não são de seu domínio, mas que serão seu instrumento de trabalho, e delas pouco retêm. Deve-se pensar em estratégias complementares que permitam uma melhor apreensão dos conteúdos, para um melhor desenvolvimento de competências digitais.
22. ROSA, Selma Santos; LEONEL, André Ary; ROSA, Valdir. Modelos pedagógicos de EaD: contribuições com a literacia digital de professores em formação. CONGRESSO BRASILEIRO DE ENSINO SUPERIOR A DISTÂNCIA - ESUD, 11., 2014, Florianópolis. Anais... Florianópolis: Universidade Federal de Santa Catarina, 2014. 
b) Manuais para usuário.

É um manual que orienta os estudantes no uso da Plataforma Moodle e do software Expression Web nas aulas na modalidade on-line.

c) Equipes de monitoria; e

d) sessões extraordinárias.

Esses são os diferentes suportes que o CED fornece aos seus estudantes com vistas a um melhor desenvolvimento da sua literacia digital.

\subsection{Estratégias para o desenvolvimento de competências digitais}

Esta pesquisa foi realizada na Universidade Católica de Moçambique - Centro de Recurso de Maputo. A implementação do e-learning nos cursos da UCM iniciou-se em 2003, na província da Beira, onde se encontra o CED ${ }^{23}$. Nesse contexto, os estudantes são oriundos das províncias de Maputo, Gaza e Inhambane, no Sul de Moçambique. Em sua maioria são trabalhadores que buscam melhorar suas competências profissionais para garantir um bom desempenho em seus sectores de trabalho. Eles estão divididos em três anos letivos: os que entraram em 2014, os de 2015 e os que ingressaram em 2016.

Neste momento, o CED tem 203 estudantes divididos pelos diferentes níveis e, como ilustra a tabela abaixo:

23. O CED tem uma coordenadora para esses cursos e quatro técnicos que a assessoram, possuindo, no total catorze Centros de Recursos.

24. TAROUCO, Liane Margarida Rockenbach et al. (Org.). Objetos de aprendizagem: teoria e prática. Porto Alegre: Evangraf, 2014.

\section{Tabela 1: Número de estudantes por ano}

\begin{tabular}{l|c|c}
\multicolumn{1}{c|}{ ANO } & N DE ESTUDANTES & NIVEL \\
Primeiro ano & 88 & Licenciatura \\
\hline Segundo ano & 103 & Licenciatura \\
\hline Terceiro ano & 6 & Licenciatura \\
\hline Mestrado & 6 & Mestrado \\
\hline Total & 203 & \\
\hline
\end{tabular}

Fonte: Elaborado pelos autores

Partindo do princípio de que a arquitetura pedagógica (AP) é uma combinação de estratégias, dinâmicas de grupo, softwares educacionais e ferramentas de apoio à cooperação direcionadas ao incremento da aprendizagem ${ }^{24}$, conclui-se que ela contempla todos os elementos intrinsecamente envolvidos na elaboração da proposta pedagógica e a sua forma de culminação. É importante, portanto, que a AP desenhada para os cursos on-line esteja clara, bem como a definição dos elementos tecnológicos inseridos na definição Plataforma Moodle em uso 
e suas funcionalidades, e os recursos destinados à promoção da comunicação (síncrona e/ou assíncrona) ${ }^{25}$.

A plataforma Moodle em uso no CED da UCM é a ferramenta que permite a troca de material e ideias entre os próprios estudantes ou entre estes e professores; os documentos (documentos orientadores, conteúdos, testes e outros materiais) são descarregados na plataforma e podem ser acessados pelos estudantes a partir de qualquer ponto em que estejam. Para orientar os estudantes, os professores utilizam a plataforma, o telefone (redes sociais) e o e-mail. Foi criado pelo CRM um fórum no WhatsApp que facilita a troca de informação entre todos; os estudantes têm também seus próprios grupos de trabalho.

As aulas são ministradas com o recurso do software Microsoft Expression Web. Com elas, os professores e estudantes podem interagir on-line para partilhar conhecimento e esclarecimento de dúvidas. Pelo Moodle, os estudantes trocam materiais e experiências de aprendizagem com seus professores, sem necessidade de se deslocarem às unidades básicas com tanta frequência, podendo até conectarem-se com seus próprios colegas de curso, em uma espécie de sala de aula virtual. A Plataforma Moodle, em si, já oferece espaços importantes de interação e comunicação síncrona e assíncrona, e a possibilidade de troca de experiências a partir dos fóruns, chats e outros materiais complementares.

Estudos já realizados confirmam que os fóruns on-line e outros espaços interativos que são característicos nesse modelo de ensino, criam oportunidades importantes para o estudante testar suas ideias e construir seu conhecimento através da aprendizagem colaborativa, pois, ao interagir com as ideias e informações, ele cresce intelectualmente. Então, o estudante constrói seu conhecimento ativamente, formulando ideias que são construídas como reação a outras ${ }^{26}$.

Pode-se considerar, nesse contexto, que a UAb de Lisboa é também uma referência em estudos na área da literacia digital dos estudantes da EaD. A instituição desenvolveu estudos que revelaram a importância da contribuição para o desenvolvimento de competências digitais que atividades nos grupos estabelecidos ao longo do curso em redes sociais virtuais - e que se mantiveram após seu término - agregaram aos estudantes, e essas tecnologias passaram a fazer parte do cotidiano desses alunos, mesmo depois do finalização do curso ${ }^{27}$. Sabe-se que o CRM criou fóruns em redes sociais (WhatsApp e Skype) que, como instrumentos comunicacionais, visam facilitar não somente a comunicação entre todos, mas o desenvolvimento de atividades em grupos (tendo em vista uma composição, normalmente, por três ou quatro estudantes cada grupo).

Ao utilizarem a internet como o único meio de interação e colaboração pedagógica entre aluno-aluno e aluno-docente, e também aluno-conhecimento, os estudantes que inicialmente não utilizavam a internet passaram a desenvolver uma literacia digital necessária para a realização do $\operatorname{curso}^{28}$. A literatura tem revelado que as investigações realizadas, em sua maioria, defendem a ideia de que basta criar um ambiente on-line, com todos os requisitos que ele exige, que as habilidades ou competências necessárias para sua utilização serão desenvolvidas; porém, realçam que um cuidadoso desenho dos cursos não é
25. BEHAR, 2007 apud BEHAR, Patrícia Alejandra; BERNARDI, Maira; SILVA, Ketia Kellen Araújo. Arquiteturas Pedagógicas para a Educação a Distância: a construção e validação de um objeto de aprendizagem. Revista Renote: Novas Tecnologias da Educação, Porto Alegre, v. 7, n. 1, n. p., 2009.

26. BATES, T. Charting the evolution of lifelong learning and distance higher education: the role of research. In: MCINTOSH, Christopher; VAROGLU, Zeinep (Ed.). Perspectives on distance education: lifelong learning \& Distance Higer Education. Paris: Unesco, 2005. p. 133-149.

27. LOUREIRO, Ana; ROCHA, Dina. Literacia digital e literacia da informação - competências de uma era digital. CONGRESSO INTERNACIONAL TIC E EDUCAÇÃO TIC EDUCA, 2., 2012, Santarém. Atas... Santarém: Escola Superior de Educação do Instituto Politécnico de Santarém, 2012.

28. ROSA, Selma Santos; LEONEL, André Ary; ROSA, Valdir. Modelos pedagógicos de EaD: contribuições com a literacia digital de professores em formação. CONGRESSO BRASILEIRO DE ENSINO SUPERIOR A DISTÂNCIA - ESUD, 11., 2014, Florianópolis. Anais... Florianópolis: Universidade Federal de Santa Catarina, 2014. 
tudo, é preciso que haja uma boa mediação, que neste caso é realizada pelo tutor. São os tutores da aprendizagem on-line que devem motivar os estudantes a alcançarem padrões de conhecimento em suas discussões nos fóruns e em outros espaços disponíveis na plataforma ${ }^{29}$.

\section{PONTOS RELEVANTES PARA CONCLUIR O ESTUDO}

A utilização das TDIC e das mídias, tais como a internet, softwares educacionais, recursos como vídeo, áudio e hipermídia na EaD, tem despertado grande interesse dos profissionais de ensino, tanto os de educação presencial como os de EaD, pois são recursos pedagógicos importantes quando pensados a partir de uma concepção do que é ensinar na contemporaneidade. Desse modo, possuir competências básicas da língua, da literacia, da numeracia e das TDIC é uma condição fundamental para que haja uma aprendizagem efetiva na sociedade contemporânea - dita como a do conhecimento e com tantas outras denominações, a partir da Web 2.0.

Para tanto, a competência digital envolve a utilização segura e crítica das tecnologias digitais da/na sociedade contemporânea, nos tempos livres e na comunicação, que é sustentada pelas competências em TDIC. É importante, portanto, que os estudantes do CRM saibam utilizar tais tecnologias, tendo em vista que estas se tornam na modalidade de EaD o principal elemento de estudo, pesquisa e sistematização de conhecimentos para, assim, obter, avaliar, integrar, produzir, cooperar, apresentar e mediar o conhecimento.

Diante desse cenário de perspectivas de um estudo em que prevalece a ótica metodológica de natureza qualitativa, torna-se necessário destacar que a análise realizada pauta-se em uma análise contextual amparada em concepções do campo da Educação. Mas, sobretudo, analisa documentos orientadores do país (Moçambique) para chegar às análises e conclusões críticas desse contexto em constantes mudanças e inovações tecnológicas, que tanto repercutem e influenciam nos sistemas da educação formal, como é o caso da EaD em Moçambique, tema aqui contextualizado.

Pode-se considerar, portanto, que existem políticas claras de inclusão digital em Moçambique, porém, há um tímido desenvolvimento de competências digitais voltado aos estudantes do EaD moçambicano, justamente pelo fato de, entre muitos fatores não mencionados aqui, haver uma deficiência da rede internet, que abarca somente a cidade e parte da província de Maputo, enquanto as zonas periféricas e rurais têm muito pouco acesso aos equipamentos informáticos, às TDIC e à própria internet.

Considera-se, ainda, que outra grande limitação está relacionada ao fato de as políticas terem tendência a apostar mais na inclusão da população urbana, em detrimento da rural, que constitui a maior parte da população moçambicana. Nesse sentido, essa análise conclui que é justamente nas regiões rurais e periféricas que devem ser iniciadas as políticas que propiciam a construção de 
A literacia digital e as estratégias para o desenvolvimento de competências na aprendizagem em EAD - Olivia Maria Matusse e Eduardo Fofonca

uma cidadania ativa, inclusiva e participativa na/da sociedade como um todo, pois os sujeitos que compõem essas regiões, de maneira geral, constituem-se como a população-alvo do estudo em questão e dos estudantes da modalidade de EaD moçambicana.

\section{REFERÊNCIAS BIBLIOGRÁFICAS}

AGUIAR, Elaine Vigneron Barreto; FLÔRES, Maria Lucia Pozzatti. Objetos de aprendizagem: conceitos básicos. In: TAROUCO, Liane Margarida Rockenbach et al. (Org.). Objetos de aprendizagem: teoria e prática. Porto Alegre: Evangraf, 2014. p. 12-28.

BATES, T. Charting the evolution of lifelong learning and distance higher education: the role of research. In: MCINTOSH, Christopher; VAROGLU, Zeinep (Ed.). Perspectives on distance education: lifelong learning \& Distance Higer Education. Paris: Unesco, 2005. p. 133-149.

BEHAR, Patrícia Alejandra; BERNARDI, Maira; SILVA, Ketia Kellen Araújo. Arquiteturas Pedagógicas para a Educação a Distância: a construção e validação de um objeto de aprendizagem. Revista Renote: Novas Tecnologias da Educação, Porto Alegre, v. 7, n. 1, n. p., 2009.

BUCUTO, Manuel; ALMEIDA, Leandro; ARAÚJO, Alexandra. Expectativas acadêmicas de estudantes universitários em Moçambique: validação de uma versão do questionário de percepções acadêmicas (QPA - Expectativas). In: SEMINÁRIO INTERNACIONAL COGNIÇÃO, APRENDIZAGEM E RENDIMENTO, 1., 2014, Braga. Anais... Braga: Universidade do Minho, 2014. p. 60-7.

CONSELHO DE MINISTROS. Estratégia da Educação a Distância 2014-2018. Maputo: Conselho de Ministros, 2013.

INSTITUTO NACIONAL DE ESTATÍSTICA. Estatísticas e indicadores sociais, 2012-2013. Maputo: INE, 2013.

INTERNATIONAL TELECOMMUNICATION UNION. Measuring the Information Society Report 2015. Geneva: ITU, 2015.

GERHARDT, Tatiana Engel; SILVEIRA, Denise Tolfo. Métodos de Pesquisa. Porto Alegre: UFRGS Editora, 2009.

JOANGUETE, Celestino. Política pública moçambicana sobre a inclusão digital. Redmarka: Revista Acadêmica de Marketing Aplicado, Buenos Aires, v. 3, n. 7, p. 61-82, 2011.

LOUREIRO, Ana; ROCHA, Dina. Literacia digital e literacia da informação - competências de uma era digital. CONGRESSO INTERNACIONAL TIC E EDUCAÇÃO TIC EDUCA, 2., 2012, Santarém. Atas... Santarém: Escola 
Superior de Educação do Instituto Politécnico de Santarém, 2012. p. 27262738.

MALEANE, Susana Otília Tomás. Tecnologias de informação e comunicação como um meio de inclusão e exclusão social em Moçambique: o caso do ensino superior. 2012. 159 f. Tese (Doutorado em Ciências da Informação) Universidade de Brasília, Brasília, DF, 2012.

MELÃO, Dulce Helena. Ler na era digital: os desafios da comunicação em rede e a (re)construção da(s) literacia(s). Exedra, Coimbra, n. 3, p. 75-89, 2010.

MINISTÉRIO DA EDUCAÇÃO DA REPÚBLICA DE MOÇAMBIQUE. Plano Estratégico da Educação 2012-2016. Maputo: Mined, 2012.

ROSA, Selma Santos; LEONEL, AndréAry; ROSA, Valdir. Modelos pedagógicos de EaD: contribuições com a literacia digital de professores em formação. CONGRESSO BRASILEIRO DE ENSINO SUPERIOR A DISTÂNCIA ESUD, 11., 2014, Florianópolis. Anais... Florianópolis: Universidade Federal de Santa Catarina, 2014.

QUIVY, Raymond; CAMPENHOUDT, Luc Van. Manual de investigação em Ciências Sociais. 2. ed. Lisboa: Gradiva, 1995.

SANTOS, Rita; AZEVEDO, José; PEDRO, Luís. Literacia(s) digital(ais): definições, perspetivas e desafios. Media \& Jornalismo, Lisboa, v. 15, n. 27, p. 27-44, 2015.

TAROUCO, Liane Margarida Rockenbach et al. (Org.). Objetos de aprendizagem: teoria e prática. Porto Alegre: Evangraf, 2014. 